\title{
Thermal evolution of terrestrial planets - implications and relevance of partition coefficient modelling
}

\author{
JULIA M. SCHMIDT ${ }^{1 *}$, LENA NOACK ${ }^{1}$, ANA-CATALINA \\ PLESA $^{2}$
}

${ }^{1}$ Freie Universität Berlin, Malteserstr. 74-100, 12249 Berlin, Germany (*correspondance: julia.schmidt@fu-berlin.de) ${ }^{2}$ German Aerospace Center, Rutherfordstr. 2, 12489 Berlin, Germany

The decay of radioactive elements such as ${ }^{40} \mathrm{~K},{ }^{232} \mathrm{Th}$ and ${ }^{238} \mathrm{U}$ provides an important contribution to the overall heat budget in the interior of the Earth and other terrestrial planets. Due to their incompatible nature in mantle rocks, melting causes these elements to redistribute from solid material into partial melt. Convective mantle motion, density variations and other physical factors cause the melt produced in the upper mantle region to move towards the surface, leading to a mantle depleted of radioactive trace elements and an enriched surface.

In this study, we model partition coefficients after Blundy and Wood 2003 [1] depending on temperature, pressure, and melt composition and trace the redistribution of radioactive elements in a global convection code. The redistribution of heat producing elements between the mantle and crust has important implications for the cooling behavior of the interior. In turn, the latter affects the generation of melt in the mantle and the formation of crust.

[1] Blundy, J.D. and Wood, B.J. (2003), RiMG, 52 (1), 59123. 